\title{
The assessment of clinical approaches and properties of benign hindfoot tumors
}

\section{Arka ayak benign kemik tümörlerinin özellikleri ve klinik yaklaşımların değerlendirilmesi}

\author{
İsmail Burak Atalay, Volkan Kaya, Şefik Murat Arıkan, Emre Özanlağan \\ Sağlık Bakanlığı Ankara Onkoloji Eğitim Ve Araştırma Hastanesi
}

Dergiye Ulaşma Tarihi:21/10/2015 Dergiye Kabul Tarihi:22/11/2015 Doi: 10.5505/aot.2015.77598

\section{ÖZET}

Amaç: Bu çalışmada kliniğimizde cerrahi tedavi uygulanan arka ayak yerleşimli benign kemik tümörlü 24 hastanın retrospektif analizinin incelenmesi amaçlanmıştır.

Yöntemler: Hastaların 18'i erkek, 6'sı kadın idi. Tümörlerin 16'sı kalkaneus, 8'i talusta idi. Hastaların hepsine açık biyopsi yapıldı ve sonucuna göre cerrahi tedavi planlandı.

Bulgular: Hiçbir hastada ameliyat içi komplikasyon olmadı. En sık karşılaşılan tümör osteokondrom idi. Postoperatif takiplerde 3 hastada enfeksiyon saptandı. Hiçbir hastada nüks saptanmadı.

Sonuç: Arka ayak yerleşimli tümör olgularında en sık başvuru şikayeti ağrı olup tanı için tümöral lezyonlar mutlaka akla getirilmeli ve tedaviye yanıtsız her hasta ileri görüntüleme tetkikleri ile değerlendirilmelidir. Özellikle talus tümörleri anatomik yapısı gereği ve teşhiste ileri radyolojik tetkikler gerektirmesi nedeniyle sıkça gözden kaçabilmektedir. Görüntüleme yöntemleri sonrasında, kesin tanı için mutlaka biyopsi uygulanmalıdır.

Anahtar Kelimeler: Benign, arka ayak tümörü, tedavi

\section{ABSTRACT}

Objective: In this study we retrospectively aimed to analyze the 24 patients with the diagnosis of benign hindfoot tumor who were surgically treated.

Methods: Eighteen of the patients were male, and six were female. Sixteen of the tumors were in calcaneus and eight were in talus. Open biopsy was performed for all the patients and the surgical planning was decided according to histopathologic results.

Results: The most common tumor was osteochondroma. Local infection was encountered in three of the patients. No intraoperative complication was recorded. No recurrence was detected in any patients.

Conclusions: The most common complaint of patients with hindfoot tumors was pain and a possible bone tumor should be kept in mind and radiological interventions should be ordered for the diagnosis of the patients unresponsive to treatment. Because of its unique anatomic structure and the requirement for detailed imaging studies, talus located bone tumors can easily be skipped. Finally, biopsy should be performed to confirm the diagnosis following radiologic interventions.

Keywords: Benign, hindfoot tumor, treatment

\section{Giriş}

Benign kemik tümörleri malign kemik tümörlerine göre daha sik görülür ve tanı yaklaşımı açısından özelleşmiş bilgi birikimi ve deneyim gerektirmesi nedeniyle ayrı bir özellik taşır (1). Tümörlü bir hasta değerlendirmesinde ilk uygulanacak adım ayrıntılı anamnez almak ve bu anamnezde yaş, cinsiyet, semptomların türü ve süresi, kitlenin lokalizasyonu ve öncesinde herhangi bir travma olup olmadığını dikkatlice sorgulamaktır. Kemik tümörlerinde en sık ilk başvuru şikâyeti ağrı olup tümörlerin en fazla yerleştiği bölge diz çevresidir. Radyografi, ilk ve temel yöntem olup bilgisayarlı tomografik inceleme ve manyetik rezonans görüntüleme de tanı ve evrelendirmede sıklıkla kullanılır. Tanı ve evrelemede en son aşama biyopsidir (2). Bütün kemik tümörlerinin içinde ise ayak tümörleri \%3 oranında yer tutar (3). Arka ayak kemikleri olarak bilinen kalkaneus ve talusta ise kalkaneus ayak tümörleri arasında metatarslardan sonra 2. sıklıkla kemik tümörü görülen yer olmaktadır. Talus ise tümöre az rastlanılan bir bölgedir (4). 


\section{Materyal - Metod:}

Bu çalışmada olarak 2003 - 2013 yılları arasında Ankara Onkoloji Hastanesinde takip ve tedavi edilmiş kalkaneus ve talus kaynaklı benign tümörü olan toplam 24 hasta klinik özellikleri yönünden değerlendirilmiştir. Değerlendirmeye alınan 24 hastanın 8'inde talus, 16'sinda kalkaneus yerleşimli lezyon bulunmaktadır. Kalkaneus yerleşimli benign tümörü olan 16 hastanın ortalama tanı alma yaş1 25 ( 4-71 yaş), talus yerleşimli benign tümörü olan 8 hastanın ortalama tanı alma yaş1 27 dir (7-42 yaş). Hastaların ortalama takip süresi 71.3 aydır. (24-120 ay)

Hastalarımızın hepsine fizik muayene, iki yönlü konvansiyonel radyografi, bilgisayarl1 tomografi ve/veya manyetik rezonans görüntüleme, tüm vücut kemik sintigrafisi ve bazı olgularda akciğer direkt grafisi yapıldı. Hastalar 1,5 aylık aralıklarla kontrole çağrıldı. Kontroller, direkt grafi ve gerekli vakalarda manyetik rezonans görüntülemesi ile yapıldı. Hastalar başvuru şikayetleri, tümör lokalizasyonları, tedavi yaklaşımları açısından değerlendirildi.

\section{Bulgular}

Takip ve tedavi edilen 24 arka ayak benign kemik tümörlü olgunun 18 'i erkek ve 6's1 kadın olup tedavi sırasında en genç hastamız 4, en yaşlı hastamız 68 ve ortalama yaş 26 idi. Hastaların en kısa takip süresi 24 ay olup ortalama takip süresi 71.3 aydır. Hiç bir benign lezyonda takip sürecinde ve son muayenesinde nüks görülmemiştir.

Hastaların en çok hastaneye başvuru şikayetleri ağrı olmaktadır (Tablo 1). Şişlik nedenli başvuru ikinci sıklıkla gözükmektedir. Basit kemik kisti tanılı 1 hasta patolojik kırıkla başvurmuştur.

Talus yerleşimli lezyonu olan hastaların tamamı öncesinde farklı merkezlerde farklı tanılarla değerlendirilmiş olup, 5 tanesi ayak bileği burkulması nedeniyle diğer 3 tanesi de yumuşak doku travması veya romatolojik hastalık yönünden tedavi görmüştür.

Tablo 1:Hastaların başvuru şikayetleri

\begin{tabular}{lll} 
& Kalkaneus & Talus \\
\hline Hasta Sayısı & 16 & 8 \\
Ağrı & $14(\% 90)$ & $8(\% 100)$ \\
Şişlik & $8(\% 50)$ & $3(\% 40)$ \\
Patolojik Kırk & $1(\% 6,25)$ & $0(\% 0)$
\end{tabular}

Talusta en sık karşılaşılan benign lezyon 3 hastayla osteokondrom olmuştur (Resim 1 ve 2). Kalkaneal tümörlerde ise intraosseöz lipom ve osteokondrom en s1k görülen benign tümörler olmuştur (Resim 3-4).

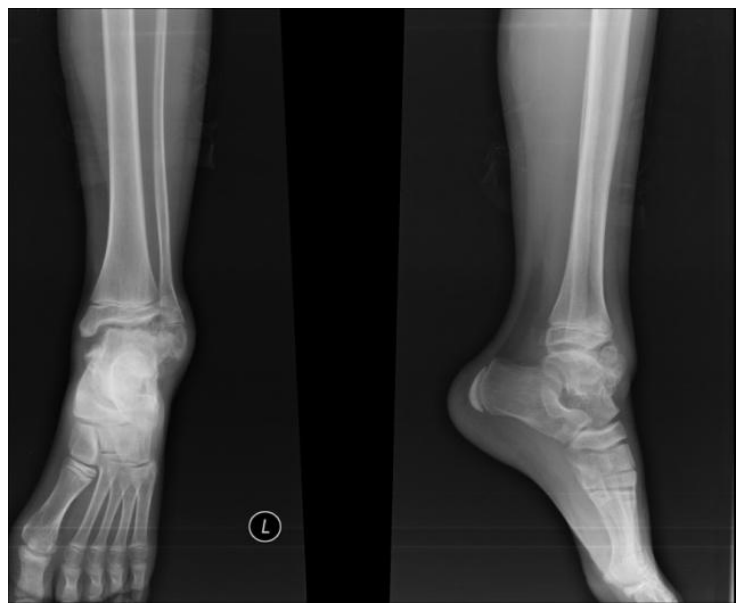

Resim 1: Talusta Osteokondrom

Hem kalkaneal hem talus yerleşimli benign lezyonların tedavisi için çeşitli yöntemler uygulanmıştır. Talus osteokondromlarına total eksizyon, dev hücreli tümör ve kondroblastom tanılı hastalara ise küretaj ve greftleme uygulanmıştır. Pigmente villonodüler sinovitli bir hastaya sinoviektomiyi takiben küretaj ve sementleme yapılmıştır. Kalkaneus yerleşimli osteokondromlara total eksizyon, diğer kalkaneus benign tümörlerine ise küretaj ve greftleme uygulanmıştır (Tablo 2 ve Tablo 3). Talus tümörlerinin takiplerinde dev hücreli tümör tanısıyla tedavisi yapılan 1 hastaya yara yeri enfeksiyonu nedeniyle antibiyotik tedavisi başlanmış ve sonrasında debritman uygulanmıştır (Resim 5). Cerrahi tedavi edilen 16 kalkaneus tümörlü hastanın takiplerinde 2 hastada lokal enfeksiyon görülmüş, bu hastaların 1 tanesine yara yeri debritmanı uygulanmıştır. Hiçbir hastada nükse rastlanılmamıştır. 

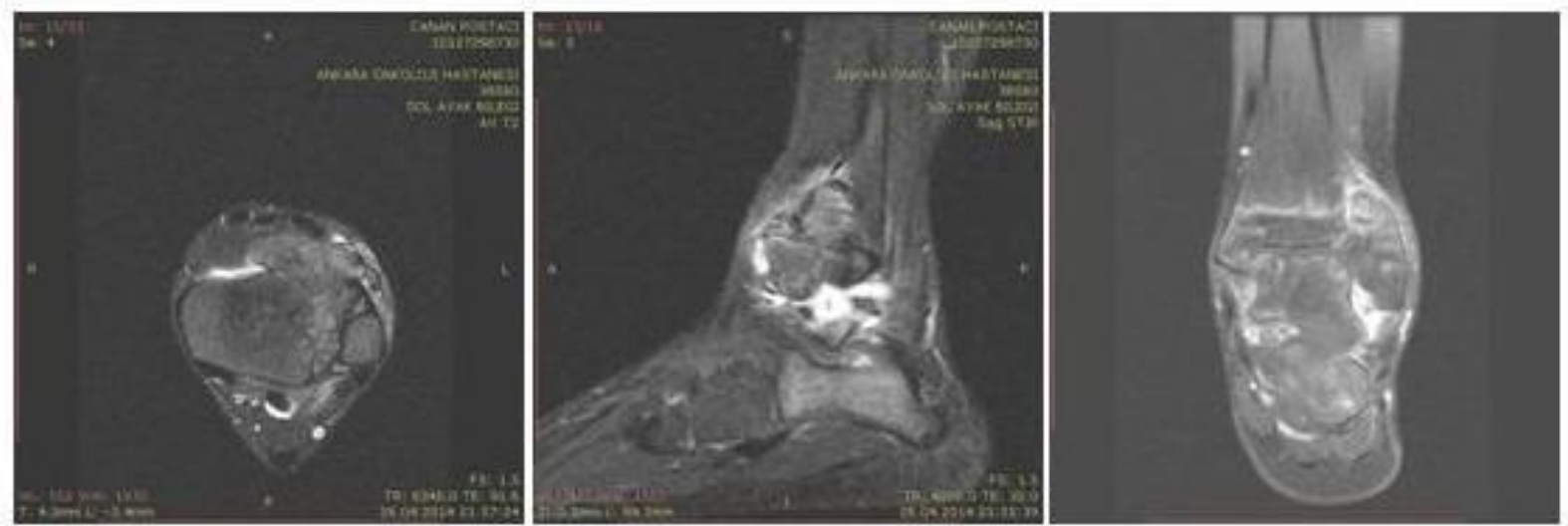

Resim 2. Talus ön yüzünden başlayıp laterale uzanan düzgün sınırlı egzofitik lezyon, osteokondrom,

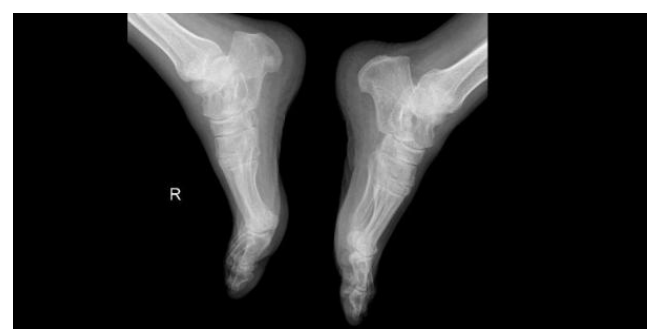

Resim 3. Sağ kalkaneus anteriorda intramedüller radyolüsen alan, kalkaneusta intraosseoz lipom
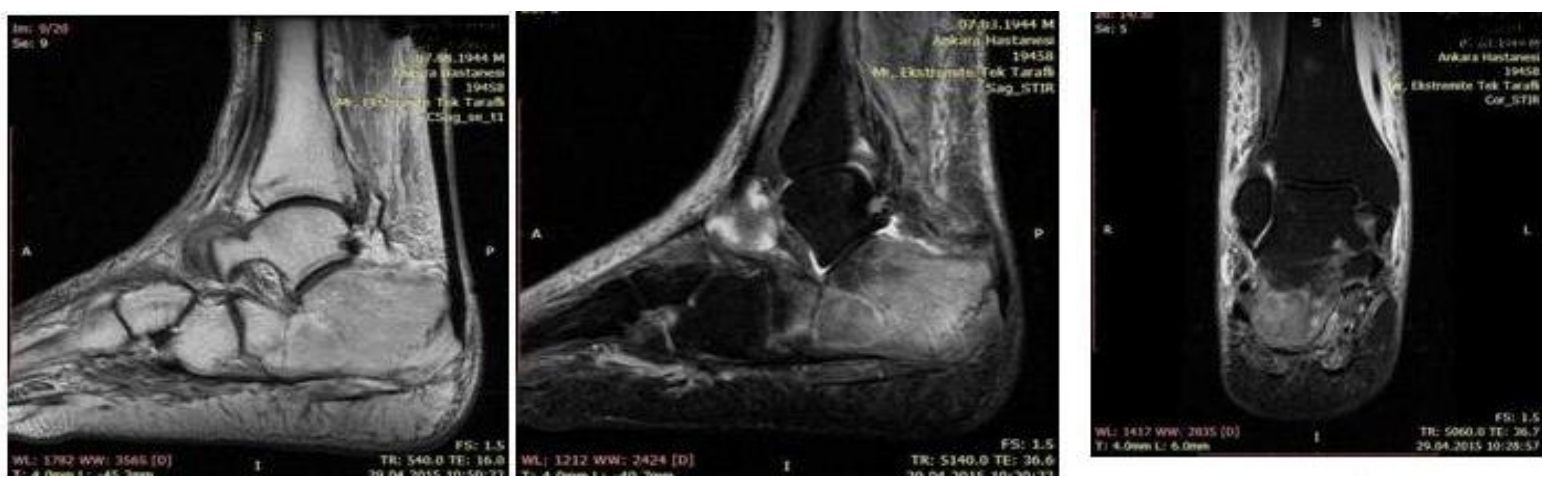

Resim 4: T1 ağırlıklı sekansda kalkaneus anteriorunda intramedüller hiperintens alan, kalkaneusta intraosseoz lipom

Tablo: 2. Benign Talus Lezyonları

\begin{tabular}{lllll} 
& Tan1 & Siniflama & Yaş/ Cinsiyet & Tedavi \\
\hline 1 & & & & \\
2 & Osteokondrom & Latent & $11 / \mathrm{K}$ & TE \\
3 & Osteokondrom & Latent & $7 / \mathrm{E}$ & TE \\
4 & Intraosseöz Lipom & Latent & $37 / \mathrm{K}$ & $\mathrm{TE}$ \\
5 & PVNS & Latent & $42 / \mathrm{E}$ & $\mathrm{K}+\mathrm{G}$ \\
6 & Dev Hücreli Tm. & Aktif & $31 / \mathrm{E}$ & $\mathrm{TS}+\mathrm{K}+\mathrm{S}$ \\
7 & Dev Hücreli Tm. & Agresif & $23 / \mathrm{E}$ & $\mathrm{K}+\mathrm{G}$ \\
8 & Kondroblastom & Agresif & 21/E & $\mathrm{K}+\mathrm{G}$ \\
& & $17 / \mathrm{E}$ & $\mathrm{K}+\mathrm{G}$
\end{tabular}

PVNS: Pigmente Villonodüler Sinovit; TS: Total Sinoviektomi; Tm: Tümör

E: Erkek; K: Kadm; TE: Total Eksizyon; K+G: Küretaj+Greftleme; S: Sementoplasti

Adress for correspondence: Uzm. Dr. İsmail Burak Atalay, Ankara Onkoloji Eğitim Ve Araştırma Hastanesi Demetevler Ankara - Türkiye e-mali: drburakatalay@gmail.com

Available at www.actaoncologicaturcica.com

Copyright $\odot$ Ankara Onkoloji Hastanes 
Tablo: 3. Benign Kalkaneus Lezyonları

\begin{tabular}{|c|c|c|c|c|}
\hline Numara & Tanı & Sinıflama & Yaş/ Cinsiyet & Tedavi \\
\hline 1 & Osteokondrom & Latent & $4 / K$ & TE \\
\hline 2 & Osteokondrom & Latent & $49 / E$ & TE \\
\hline 3 & Osteokondrom & Latent & $37 / K$ & TE \\
\hline 4 & Osteokondrom & Latent & $17 / \mathrm{E}$ & TE \\
\hline 5 & Intraosseöz Lipom & Latent & $71 / \mathrm{E}$ & $K+G$ \\
\hline 6 & İntraosseöz Lipom & Latent & $42 / E$ & $K+G$ \\
\hline 7 & Intraosseöz Ganglion & Latent & $48 / K$ & $K+G$ \\
\hline 8 & İntraosseöz Lipom & Latent & $32 / \mathrm{E}$ & $K+G$ \\
\hline 9 & İntraosseöz Lipom & Latent & $28 / E$ & $K+G$ \\
\hline 10 & Basit Kemik Kisti & Aktif & $15 / K$ & $K+G$ \\
\hline 11 & Basit Kemik Kisti & Aktif & $16 / E$ & $\mathrm{~K}+\mathrm{G}$ \\
\hline 12 & Basit Kemik Kisti & Aktif & $16 / \mathrm{E}$ & $K+G$ \\
\hline 13 & Enkondrom & Aktif & $59 / K$ & $K+G$ \\
\hline 14 & Enkondrom & Aktif & $68 / \mathrm{E}$ & $K+G$ \\
\hline 15 & Anevrizmal Kemik Kisti & Agresif & $10 / \mathrm{E}$ & $K+G$ \\
\hline 16 & Kondroblastom & Agresif & $14 / E$ & $\mathrm{~K}+\mathrm{G}$ \\
\hline
\end{tabular}

E: Erkek; K: Kadın; TE: Total Eksizyon; K+G: Küretaj+Greftleme
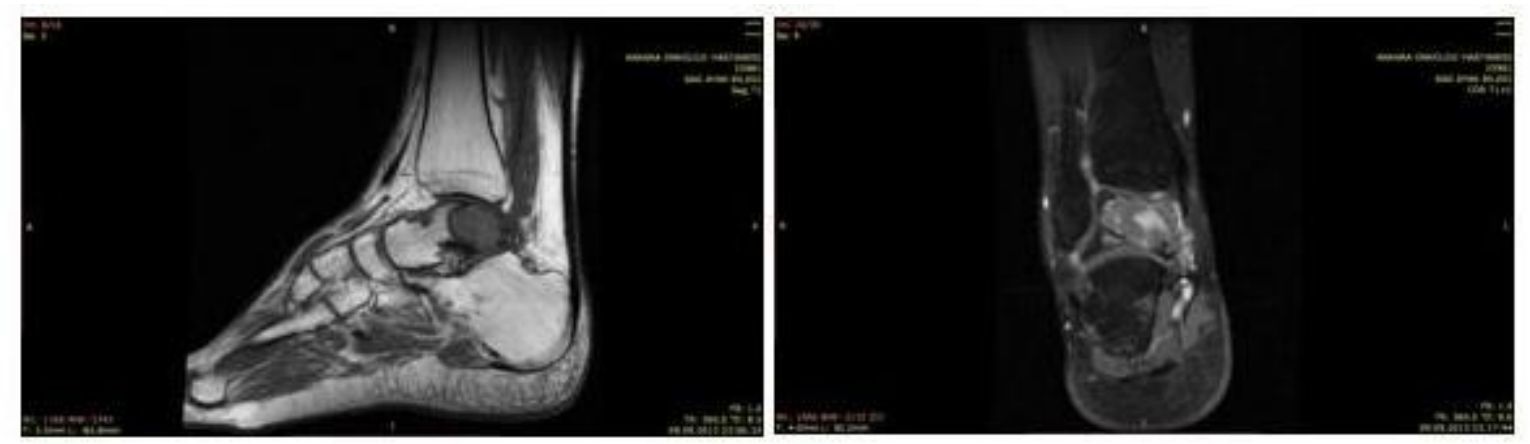

Resim 5. T1 ağırlıklı sekansda talus posteriorunda intramedüller hipointens alan, talusta dev hücreli tümör

\section{Tartışma}

Tüm tümörler içinde kemik tümörleri $\% 0.2$ oranında görülmekte, ayak tümörleri ise tüm kemik tümörlerinin \%3'ünü oluşturmaktadır. Ayak kemik tümörleri nadir görülmekle birlikte işgücü kayb1, tanı ve tedavideki olası yaklaşım problemleri açısından önemlidir.
Arka ayak kemik tümörleri çok az görülen ve üzerine çok sınırlı sayıda çalışma yapılmış tümörlerdir. Aynı zamanda geç ve yanlış tanı konması çok sıklıkla bildirilmiştir. Bunun sebebi az görülmesi ve çoğu hekimin çok bilmediği bir tümör grubu olmasından kaynaklıdır $(5,6)$.

Kemik tümörlü bir hastanın değerlendirmesinde ilk adım ayrıntılı

Adress for correspondence: Uzm. Dr. İsmail Burak Atalay, Ankara Onkoloji Eğitim Ve Araştırma Hastanesi Demetevler Ankara - Türkiye 
anamnezdir. Yaş, cinsiyet, semptomların süresi, kitle lokalizasyonu değerlendirilmelidir. Ağr1 en sıklıkla rastlanılan semptomdur. Benign tümörler mekanik olarak basıya veya patolojik kırığa neden olmadıkça genellikle ağrısızdır $(7,8)$.

Tümörün mekanik etkisi sonucu eklem hareketlerinde kısıtlanma gözlenebilir. Tümör direkt olarak ayak bilek eklemini etkileyebildiği gibi, reaktif sinovit sonras1 eklem hareketlerinde kısıtlanma ve ağrıya da yol açabilir (9).

Kalkaneal tümörlü hastalar genellikle topuk ağrısı, talar tümörlü hastalarda genellikle ayak bileği ağrısı şikayetiyle kliniklere başvururlar. Ağrı genel olarak sürekli olmakla birlikte bazen de ağrıya şişlik eşlik etmektedir. $\mathrm{Bu}$ sebeple bu şekilde gelen hastalarda ayak bileği veya topukta yumuşak doku travması düşünülerek yanlış tanı konulabilmektedir $(10,11)$.

Kemik tümörlerinin değerlendirilmesinde laboratuvar testleri genellikle yetersizdir. Radyoloji, klinik muayenenin tamamlayıcısıdır ve çoğu kez klinik muayeneden elde edilen bilgilerden daha fazlasını verir. Radyolojik muayenenin amac1, tümörü taklit edebilecek diğer patolojilerin ayırt edilmesi, tümörün doğası ve yayılımının belirlenmesi, biyopsi için uygun dokunun saptanması ve tedavinin takibidir $(8,11)$.

Kemik tümörlerinin değerlendirilmesi röntgen ile başlar. Kemik tümörlü hastaya yaklaşımda bir sonraki adımın ne olacağına radyografiden elde edilen bilgilere göre karar verilir. Çoğu benign kemik tümörü ve tümör benzeri lezyonun tanisi radyografi ile konulabilir ve ek radyolojik incelemeye veya biyopsiye gerek kalmaz $(8,12,13)$. Manyetik rezonans görüntüleme kemik tümörlerinin yayılımının belirlenmesinde en değerli yöntem kabul edilir. Tümörün komşu kas grupları, nörovaskuler yapılar ve ekleme invazyon yapıp yapmadığı manyetik rezonans inceleme ile saptanabilir (14,15). Sintigrafi kemik lezyonlarını spesifik olmayan şekilde gösterir. Klinik olarak önemi cerrahi operasyon sınırını belirleme ve evrelemedir. Kemik metastazlarını göstermede direkt grafilere göre duyarlılı̆g 1 daha yüksek olup daha ekonomiktir. Normal bir sintigrafi sonucu bir lezyonun büyük olasılıkla benign olduğunu gösterir, fakat anormal bir sintigrafi sonucu malign benign ayırımı yapamaz $(8,15,16)$. Biyopsi değerlendirme ve evrelendirme sürecinde en son aşamadır. Biyopsi tüm malign tümörlerin ve çoğu benign lezyonların tedavisinde gerekebilir. Biyopsi olmaksızın radyolojik tanı basit kemik kisti, osteokondrom, fibröz kortikal defekt gibi çeşitli benign lezyonlar için güvenle konabilir. USG eşliğinde iğne biyopsisi açık biyopsiye göre daha az invaziv bir yöntemdir ancak yapılamadığı durumlarda BT eşliğinde veya açık biyopsi yapılmalıdır $(15,17)$. Eksizyonel biyopsi genelde yumuşak doku tümörlerinde tercih edilir, büyük ve malignite süphesi olan tümörlerde yapılmamalıdır. İnsizyonel biyopsi tüm kemik ve yumuşak doku kitlelerine uygulanabilir (18).

Sonuç olarak arka ayak kemik tümörlü olguya sistematik bir yaklaşım gerekmektedir. Benign tümörler mekanik olarak basıya ya da patolojik kırığa neden olmadıkça genellikle ağrısız olmalarına rağmen yine de en sik başvuru şikayetinin ağrı olduğu gözden kaçırılmamalıdır. En sık karşılaşılan fizik muayene bulgusu palpabl bir kitle varlığıdır. Kalkaneus talusa göre daha sik etkilenir. Talus lezyonları kalkaneustakilere oranla kemiğin lokalizasyonu ve direk grafilerle görünürlüğü açısından daha zor tanı alır ve daha kolay atlanabilir. Arka ayak kemik tümörlerinin tanısının konulabilmesi için tümöral lezyonlar mutlaka akla getirilmeli ve tedaviye yanitsız her hasta ileri görüntüleme tetkikleri ile değerlendirilmeli, sonrasında uygun biyopsi yöntemleri ile tanısal yaklaşım sonlandırılmalidır.

\section{Cıkar Çatışması: Yok}

\section{Kaynaklar}

1. Enneking WF, Spannier SS, Goodman MA. A system fort he surgical staging of musculoskeletal sarcoma. Clin Orthop 2003;415:4.

2. Karakurt L, Yilmaz E, Varol T, Özdemir H. Dirsekte soliter osteokondroma bağlı gelişen ulnar sinir basıs1: Olgu Sunumu. Açta Orthop Traumatol Turc 2004;38:291-4.

3. Unni KK, Dahlin DC. Dahlin's Bone Tumours: General Aspects and Data on 11087 Cases. 5th ed. Philadelphia, PA, USA: Lippincott-Raven; 1996. 
4. Murrari TM, Callaghan JJ, Berrey BH Jr, Sweet DE. Primary benign and malignant osseous neoplasms of the foot. Foot Ankle. 1989;10:68-80.

5. Lawrence W JR. Soft tissue sarcomas in adults and children.A comparison CA. CancerJ Clin 1994;44:197-9.

6. Bakotic B, Huvos AG. Tumors of the bones of the feet: the clinicopathologic features of 150 cases. J Foot Ankle Surg. 2001; 40:277-286.

7. Biscaglia R, Gasbarrini A, Bohling T, Bacchini P, Bertoni F, Picci P. Osteosarcoma of the bones of the foot-an easily misdiagnosed malignant tumour. Mayo Clin Proc. 1998;73:842-847.

8. Bloem IC, Mulder JD. Chondroblastoma: a clinical and radiological study of 104 cases. Skeletal Radiol. 1985;14:1-9.

9. Güngör Ş, Karakoç Y, Arıkan M, Metin E, Gürler D. Çocukluk Çağı Benign Kemik Tümörlerinin Demografik Özellikleri ve Klinik Yaklaşımlarının Değerlendirilmesi . Acta Oncologica Turcica 01/2008; 41(1):7-13

10. James O, Johnston; Tumors in ortopedics. Current Diagnosis and Treatment in Ortopedics, Harry B. Skinner, 1995:236-314.

11. Herring JA, (editör). Benign musculoskeletal tumors. ln:Tachd]ian's pediatric orthopaedics. 3rd ed. Philadelphia: W.B. Saunders, 2002:1897.

12. Kerns LL, Simon MA. Surgical theory, staging and surgery of muskuloskeletal neopiasms. Orthop Clin North Am 1996;27:473.

13. Engin K, Sağlık Y, Aydınlı U. Kemik ve Yumuşak Doku Tümörleri. Klinik Değerlendirme ve Görüntüleme, 2005:27.

14. DeBenedetti MJ, Waugh TR, Evanski PM, Jordon I, Krijger M. Chondrosarcoma of the talus: a case report. Clin Orthop Relat Res. 1978;136:234-237.

15. Woertler K. Benign bone tumors and tmors tike lesions: Value of cross sectional imaging. Eur Radiol 2003; $13: 1320$.

16. Sundaram M. Magnetic resonance imaging for solitary lesions of bone: When, why, how useful? J Orthop Sci 1999; 4:383.

17. Magid D. Two-dimensional and three dimensional computed tomographic imaging in musculoskeletal tumors. Rdaiol Clin North Am 1993;31:425.

18. Simon M, Kirschner P: Scintipgraphic evalution of primer bone tumors. J Bone Joint Surg 1980;62A.758.

19. Mankin HJ, Langin TA, Spanier SS: The hazards of the biopsy, J Bone Joint Surg 1996;78-A:656-63. 